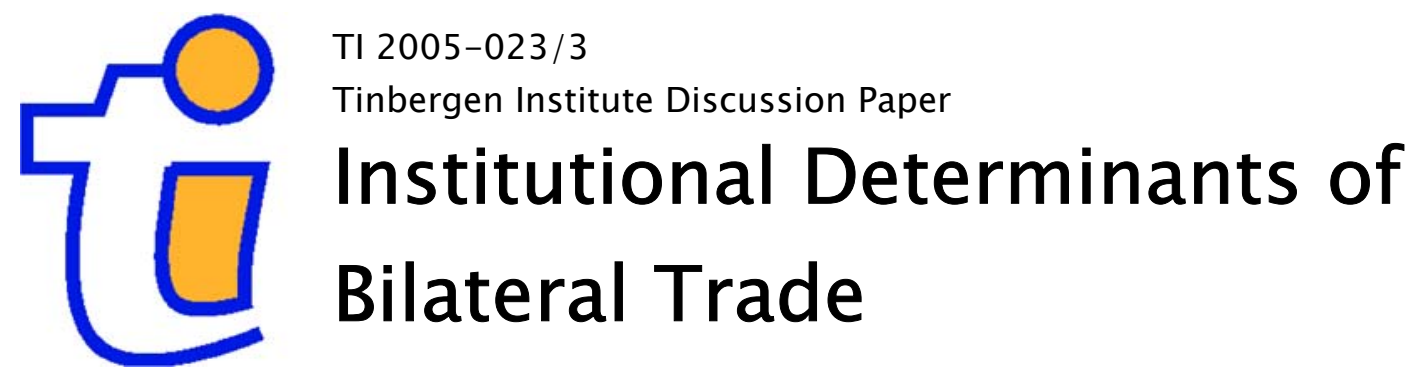

Gert-Jan M. Linders

Henri L.F. de Groot

Piet Rietveld

Department of Spatial Economics, Vrije Universiteit Amsterdam, and Tinbergen Institute. 


\section{Tinbergen Institute}

The Tinbergen Institute is the institute for economic research of the Erasmus Universiteit Rotterdam, Universiteit van Amsterdam, and Vrije Universiteit Amsterdam.

Tinbergen Institute Amsterdam

Roetersstraat 31

1018 WB Amsterdam

The Netherlands

Tel.: $\quad+31(0) 205513500$

Fax: $\quad+31(0) 205513555$

Tinbergen Institute Rotterdam

Burg. Oudlaan 50

3062 PA Rotterdam

The Netherlands

Tel.: $\quad+31(0) 104088900$

Fax: $\quad+31(0) 104089031$

Please send questions and/or remarks of nonscientific nature to driessen@tinbergen.nl.

Most TI discussion papers can be downloaded at http://www.tinbergen.nl. 


\title{
Institutional Determinants of Bilateral Trade
}

\author{
an analysis according to product type
}

\author{
Gert-Jan M. Linders, Henri L.F. de Groot, Piet Rietveld* \\ Department of Spatial Economics, Vrije Universiteit Amsterdam and Tinbergen Institute \\ De Boelelaan 1105, 1081 HV Amsterdam, The Netherlands
}

\begin{abstract}
Formal trade barriers and transport costs explain only part of the resistance to international trade. Search costs on the international market and insecurity of property rights and contract enforcement have recently been emphasized as important intangible barriers to trade. This paper proposes that the impact of institutional quality on bilateral trade varies depending on the type of product that is being traded. Distinguishing between homogeneous and differentiated product groups, we estimate gravity equations to investigate how trade patterns are affected by variation in the quality of institutions across countries. The results show that institutions matter most for trade in differentiated goods. This variation in the importance of property security for trade underlines the relevance of search costs and other transactionspecific investments for understanding variation in bilateral trade patterns.
\end{abstract}

JEL codes: F14, F15

Keywords: bilateral trade, gravity model, institutions, trade costs, product type

* Corresponding author: G.M. Linders, Department of Spatial Economics, Vrije Universiteit, De Boelelaan 1105, 1081 HV Amsterdam, The Netherlands, Tel: +31 204446106 (6090), Fax: +31 20 444 6004, Email: glinders@feweb.vu.nl. We gratefully acknowledge the World Bank for permission to use the WITS interface. We also thank Uma Subramanian from the World Bank for useful and stimulating discussions that contributed to this paper. Furthermore, the authors would like to thank Jaap de Vries and Andrés Rodríguez-Pose for helpful suggestions and comments. 


\section{Introduction}

The size of international trade flows is much smaller than trade theory would predict. This has been documented by Trefler (1995) as the missing trade mystery, and was convincingly illustrated by the border effect, or home bias to trade (McCallum 1995; Anderson and Van Wincoop 2003). Formal trade barriers and transport costs explain only part of the resistance to international trade. Apparently, unobserved trade costs are important for understanding the patterns of trade (Anderson and Van Wincoop 2004; Deardorff 2004; Obstfeld and Rogoff 2001; Anderson 1999). Search costs in the international market place and insecurity of property rights and contract enforcement have recently been emphasised as potentially important intangible barriers to trade (Rauch 1999; Anderson and Marcouiller 2002; De Groot et al. 2004). Search costs are relevant because most products are not sold on organized exchanges. Acquisition of information on product supply and demand is costly, especially for distant and unfamiliar markets. The search for a trade partner is especially costly for differentiated products, whose international market conditions are least transparent. Property security and contract enforcement is problematic in international exchange. Because trade involves multiple legal and political systems, enforcement of contracts is more difficult and transactions are exposed to increased risk of corruption and theft. The effectiveness of domestic institutions in securing property and enforcing contracts is a crucial element in determining the risk of exposure to opportunistic behaviour in trade.

In this paper, we argue that trade costs caused by property and contract insecurity vary according to product type. Relation-specific search and adjustment costs are higher for transactions in differentiated products. Therefore, the risk and costs of exposure to opportunistic behaviour are higher. We estimate gravity equations of bilateral trade, disaggregated according to product type and show that property insecurity indeed matters most for trade in differentiated products. This variation in the importance of property security 
for trade underlines the relevance of search costs and other transaction-specific investments for understanding variation in bilateral trade patterns.

The paper proceeds as follows. In section 2, we review more closely the arguments that link unobserved trade costs to search processes and property insecurity in the international market place, and argue that both views are complementary. Section 3 introduces the data and empirical method used for analysis. The empirical results are presented in section 4 . We will separately deal with the problems caused by the prevalence, at a disaggregated level, of zerovalued bilateral trade flows. Finally, section 5 presents conclusions and some suggestions for further research.

\section{The network and insecurity views of informal trade barriers}

\subsection{The network view}

To understand how trade patterns evolve, recent studies have pointed at the importance of networks, rather than atomistic markets (e.g., Rauch 1999, 2001). The search/network view starts from the observation that a majority of products is not traded on organized exchanges. Therefore, search processes are important in order to match buyers and sellers. Networks serve to facilitate the search for suitable trade partners. As a result, understanding the characteristics and development of networks is important to explain the observed patterns of trade.

Rauch (1999) classifies products according to product type. Homogeneous products differ from differentiated goods in the use of 'markets' as opposed to networks for exchange. Homogeneous goods can be compared exclusively on the basis of price differences. Several homogeneous products are traded on an organized exchange where supply and demand directly confront and match. Many other homogeneous products are sold on a decentralized 
market where the 'invisible hand' of the price mechanism takes care of co-ordination. Although not frictionless, matching resembles a perfectly competitive centralized market, where the comparison is based on prices as the only relevant characteristic. For these products, reference prices are often published, illustrating global competitiveness through the possibility for international arbitrage of price differences. Differentiated products cannot be compared on the basis of prices alone. Price differences must be adjusted for differences in characteristics and quality between the varieties. The relative importance of the various characteristics differs across countries depending on the available supply and preferences that prevail (Rauch 1999, p. 9). In the end, each variety has its own unique blend of characteristics. The product is 'branded', and has its own supplier. Because of the difficulty of comparing differentiated products, differentiated products cannot be traded on organized exchanges. ${ }^{1}$ Moreover, information costs are so high that international arbitrage by specialized traders across varieties is not feasible either. Instead, differentiated products are traded through networks by search and match between traders, customers and suppliers. Rauch (1999) argues that the process of search is facilitated by factors that improve the information flow and knowledge of foreign markets. He refers to shared language, colonial links and geographical proximity as search-enabling factors, because they increase bilateral familiarity and decrease 'psychic distance' (see Frankel 1997).

Rauch (1999) identifies three product groups that reflect the 'network versus market' distinction in trade. Homogeneous products comprise two groups: products traded on an organized exchange and reference-priced articles; the third group consists of differentiated goods. The network theory of trade hypothesizes that search costs are most important for the pattern of trade in differentiated products and least important for organized-exchange

\footnotetext{
1 An organized exchange would not be plausible either, because monopolistic competition prevails in differentiated product industries. Given that a firm is the single supplier of its brand, it will recognize its product's imperfect substitutability and set a price rather than participate in a competitive tâtonnement process.
} 
products. Hence, we expect proximity, language and colonial links to be particularly important for trade in differentiated products.

\subsection{Insecurity of property and trade}

Recently, an alternative explanation for unobserved trade costs has been offered, focusing on variation in institutional effectiveness across countries. The unobserved barriers to trade are often related to incomplete or asymmetric information and uncertainty in exchange. North (1990) argues that, because of imperfect insight and incomplete information, people form institutions. He defines institutions as 'humanly devised constraints that shape human interaction' $(1990$, p. 3). These rules of the game are intended to reduce the uncertainty in exchange, and lower transaction costs. A poor institutional environment, in terms of property rights protection and contract enforceability, entails negative externalities for private transactions and consequently raises transaction costs. As a result, the quality of governance is an important determinant of economic growth and development (see, e.g., Olson 1996). Institutional economics has recently been extended into the field of international economics (e.g., Dixit 2004; Anderson and Marcouiller 2002; Wei 2000). This approach states that insecurity of property and contract enforcement imposes high costs on trade. Rodrik (2000, p. 179) argues that the transaction-cost problem of contract enforcement is aggravated for international trade, compared to domestic exchange. International trade involves at least two jurisdictions, which makes contract enforcement more difficult. This discontinuity in the political and legal system increases uncertainty and the risk of opportunistic behaviour by either party to the exchange. Accordingly, the effectiveness of legal and policy systems in providing law and order, securing contract enforcement and facilitating trade is an important 
determinant of bilateral trade costs. ${ }^{2}$

\subsection{Complementarity of the search and insecurity views}

Network/search theory and institutional theory offer credible explanations for the origin of unobserved trade barriers. The insecurity view argues that bilateral trade will be lower when property is less secure, while network theory stresses the importance of search costs for trade in differentiated products. Both approaches have developed more or less independently. For example, Anderson and Marcouiller (2002, p. 343) indicate that their analysis does not explicitly consider the role of networks in reducing information costs and facilitating trade. Alternatively, Rauch (1999) does not consider the implications of asymmetric information for contract enforcement in trade. However, there is sufficient overlap in the underlying features of both approaches to consider a combination of hypotheses.

The kinship between institutional and network/search theories of trade costs is apparent. Anderson and Marcouiller (2002) note that the insecurity and information-based models overlap 'to the extent that information about exposure to misappropriation matters'. Amongst others, Rauch (2001), Rauch and Trindade (2002) and Dixit (2004) refer to networks as informal mechanisms to enforce cooperative behaviour. Anderson and Van Wincoop (2004) argue that the effect of ethnic networks on trade found in Rauch and Trindade (2002) can hardly be due to information costs alone. As contracts are often complex and necessarily incomplete, contracting and enforcement costs are likely to be important as well to explain the importance of networks in trade. Informal governance structures, such as networks of business and social relations, substitute for weak formal contract enforcement. The characteristic of networks that enables them to curb opportunistic behaviour has been termed

\footnotetext{
2 Anderson and Marcouiller (2002) and De Groot et al. (2004) offer empiri cal support for the effect
} of governance quality on bilateral trade patterns. 
'closure'. This refers to the existence of sufficient mutual links between network members, in a setting of repeated interaction, such that norms of cooperative behaviour can be propagated and reneging is signalled and can be sanctioned (Coleman 1988).

Network closure is easier to accomplish when markets are more or less stable, e.g., in the domestic context (Rodrik 2000). In global markets, tight networks sometimes lack the openness to new opportunities and trading partners that is needed to widen the scope of trade (Greif 1994). Historically, tight networks have solved this by migrating to new markets, thereby establishing ethnic links that propagate the network (see, e.g., Rauch and Trindade 2002; Rauch 2001). Alternatively, trade networks may expand by focusing on 'weak' ties, which do not focus on kinship or ethnic relations exclusively. Granovetter (1985) referred to the role of weak ties in propagating networks as the 'strength of weak ties'. In general, however, openness comes at a price. Closure by intense mutual ties of repeated contact within networks becomes more difficult to obtain in open networks that continuously renew and extend their scope (cf. Dixit 2004 and Rodrik 2000). The use of networks focuses more on signalling new opportunities and lowering search costs, instead of acting as tight informal governance structures. The reach of informal governance becomes more limited, which invokes the need for formal institutions to protect property rights. The limit to networks in securing property, however, is complemented by problems to secure trade by more formal legal systems as markets grow larger, most notably when exchange involves multiple jurisdictions (Dixit 2004; Rodrik 2000). In fact, trade drops dramatically when exchange crosses national borders. This has been documented as the 'border effect' in trade (e.g., McCallum 1995).

Trade relations in differentiated goods tend to be characterized by incomplete contracts and long-term, repeated interaction. Because of product differentiation, supplier and buyer in general have to engage in specific investments to establish and maintain their relationship. 
Search costs and product differentiation raise the asset-specific investments that both parties have to incur in trade. In such a situation of bilateral dependencies, repeated interaction can raise incentives for opportunistic behaviour. The risk of opportunism creates the possibility of hold-up problems (see, e.g., Grout 1984, Van der Ploeg 1987 and Caballero and Hammour 1996, for analyses of hold-up problems). Legal and political systems are important to curb the risk of opportunism in trade. International exchange is especially vulnerable to opportunism. Therefore, the effectiveness of the institutional environment is an important determinant of the decision whether or not to invest in bilateral trade relations. Moreover, although networks are arguably less effective as enforcement mechanism on the international market, the risk of opportunistic behaviour still provides a rationale for the importance of selective networks for trade flows, in particular for differentiated goods. For homogeneous products, the risk and costs of opportunistic behaviour are less severe. The trade relation remains 'at arm's length', curbing the costs of opportunistic behaviour by greater possibilities to diversify or substitute away from defectors, due to competitive discipline. Moreover, product homogeneity allows more complete and transparent contracts, which can focus on prices. Still, if the reach of markets extends (across national boundaries), effective enforcement of contracts becomes more difficult for homogeneous products as well (Dixit 2004).

In this paper, we investigate whether the impact of institutional quality on bilateral trade depends on the type of product that is being traded. We would generally expect the costs of property insecurity and low contract enforceability to be lowest for organized-exchange products, because diversification is easiest there. Specialized traders can diversify systemic risk of contract breach by ordering from many different suppliers, without any concern left for final customers. For reference-priced commodities, the need for more case-specific search raises search costs and the incentive to enter into closer relations. Trade will increasingly avoid environments with low contract enforceability. This leads to a set of hypotheses that 
resemble those suggested by Rauch (1999) on the relevance of search costs for trade. More specifically, we empirically test whether property rights and contract enforcement institutions are more important for trade in differentiated goods than for trade in homogeneous goods. Inadequate legal and political systems are expected to affect trade patterns most severely for differentiated products, and least so for organized-exchange products. Moreover, just as colonial and language links facilitate search, they are also likely to increase trader's skills to operate effectively in each other's institutional settings (Anderson and Marcouiller 2002). This provides an additional reason to expect a higher effect from historical links on trade in differentiated products.

The remainder of this paper investigates these hypotheses more closely by estimating institutions-augmented gravity equations to explain bilateral trade in differentiated, referencepriced and organized-exchange commodities. The next section discusses the data and the empirical model.

\section{Data and method}

\subsection{The gravity model of bilateral trade}

In order to identify the effects of institutions on bilateral trade, we estimate gravity equations on trade flows. The gravity model owes its name to the fact that it relates bilateral trade proportionately to the economic 'mass' of the country pair (reflected by GDPs), and inversely to the distance between them. The use of gravity models to analyse trade patterns has a long tradition, dating back to the 1960s at least (see Frankel 1997 for an overview). Although it has always been successful in providing economically and statistically significant results, and explains most variation in bilateral trade (Rose 2003), the gravity model has been criticized for a lack of theoretical foundation. However, several contributions have been made to 
address the relation between trade theory and the gravity model. These have shown that the gravity model is consistent with both Heckscher-Ohlin type models of trade and models of monopolistic competition, economies of scale and intra-industry trade (e.g., Evenett and Keller 2002; Deardorff, 1998 and Helpman and Krugman 1985).

The basic version of the gravity equation that we estimate looks as follows:

$$
\begin{aligned}
& \ln \left(T_{i j}\right)=\beta_{0}+\beta_{1} \ln \left(Y_{i}\right)+\beta_{2} \ln \left(Y_{j}\right)+\beta_{3} \ln \left(y_{i}\right)+\beta_{4} \ln \left(y_{j}\right)+\beta_{5} \ln \left(D_{i j}\right)+\beta_{6} \text { Adj }_{i j} \\
& +\beta_{7} \text { Lang }_{i j}+\beta_{8} \text { PTA }_{i j}+\beta_{9} \text { Religion }_{i j}+\beta_{10} \text { Col }_{i j}+\beta_{11} \text { Inst }_{i}+\beta_{12} \text { Inst }_{j}+\beta_{13} \text { InstDist }_{i j}+\varepsilon_{i j}
\end{aligned}
$$

where $i$ and $j$ denote the exporting and importing country, respectively. Our dataset comprises 114 countries. The dependent variable $T_{i j}$ is aggregate merchandise exports (in '000 US\$) from $i$ to $j$ for 1998. The independent variables are, respectively: GDP (Y), GDP per capita $(y)$, the distance between $i$ and $j\left(D_{i j}\right)$ and dummies reflecting whether $i$ and $j$ share: a land border (Adj), their primary language (Lang), membership in a regional Preferential Trade Agreement $(P T A)$, their main religion (Religion), and whether they were part of a common colonial empire $(\mathrm{Col})$. The variables of particular interest in this paper deal with the institutional framework. The first two reflect the level of subjective institutional quality (Inst) in both countries. The quality of the legal and policy system also conditions informal norms of behaviour and inter-personal trust, which influence the procedures of doing business in a country. The degree of familiarity with the institutional environment in another country may influence risk perceptions and preferences for international trading partners (De Groot et al. 2004). Bilateral distance between the institutional systems, in terms of effectiveness, is reflected in the variable InstDist. The last term is the stochastic error term, which captures all other (omitted) effects on trade and is assumed to be well behaved. 
The specification adopted in this paper closely follows Rauch (1999) in spirit. However, we separate the influences of language and colonial ties, and add a variable reflecting cultural links as expressed in the main religion adhered to. Moreover, we specifically focus on the impact of cross-country variation in institutional quality on the patterns of trade.

The standard loglinearized gravity model can only deal with observations of bilateral trade that are strictly positive. In a large data set of bilateral trade, some of the potential trade flows will in practice be recorded as zero or missing. Apart from reporting errors, this reflects trade flows that are too small to register, or that are truly zero. Omitting zero flows can lead to biased results, if the distribution of positive trade flows is distorted by the zero-trade censoring level. Section 4.2 will discuss a modification to the gravity equation that allows us to include zero-flow observations in the analysis and to establish the robustness of our basic results that we describe in section 4.1 .

\subsection{The data}

For data on the quality of governance systems, we use the database constructed by Kaufmann et al. (2003). Drawing on 17 different sources of subjective institutional quality, they have constructed six indicators of perceived institutional quality. Each indicator captures a different aspect of governance. These indicators are:

1. Voice and Accountability: reflects the political process and includes the independence of the media;

2. Political stability: includes the likelihood that the government will be overthrown by unconstitutional interference and reflects the stability of the economic environment; 
3. Government effectiveness: measures the quality of public service provision, the independence of the bureaucracy, and the competence of civil servants. More generally, it reflects the ability of the government to formulate and implement good policies;

4. Regulatory quality: reflects the quality of the implemented policies, like the degree of over-regulation of business development and the incidence of market-unfriendly policies;

5. Rule of law: measures the degree to which citizens have confidence in the law and abide by the rules of society. It concentrates on the quality of the legal system and the enforceability of contracts;

6. Control of corruption: reflects the degree to which public power is exercised for private gain.

All aspects of governance are interrelated. As a result, the indicators are highly positively correlated. An investigation of homogeneity using Cronbach's alpha suggests that all indicators reflect a single latent variable. ${ }^{3}$ Consequently, we can regard all of them as measures of the overall quality of governance. For that reason, we have aggregated the six indicators into a composite measure of institutional quality. The simple arithmetic average of the scores on each separate indicator serves as the composite indicator. Similarly, we have constructed a single indicator of institutional distance, reflecting bilateral distance in terms of

\footnotetext{
3 Cronbach's alpha $(\alpha)$ measures how well a set of variables reflects a single underlying latent variable; this reflects the internal consistency (or validity) of an overall scale based on the set of variables. The coefficient was originally developed to assess the internal consistency of a set of questions (items), as on a survey form (Cronbach 1951). We use it to assess whether we can combine the six indicators of institutions into a single overall indicator. The calculation of $\alpha$ is based on the average correlation among pairs of the indicators. Cronbach's alpha varies between 0 and 1 (for nonnegatively correlated variables). If the indicators are perfectly correlated, then $\alpha=1$; if they are completely unrelated, $\alpha=0$. If $\alpha$ is high (close to 1 ), this indicates a high degree of internal consistency. Generally, a value of 0.8 or above indicates sufficient internal consistency. The $\alpha$ score for the six indicators of institutions is 0.96 . Thus, they reflect the same underlying characteristic and can be combined into a single scale. In this way, we can use all information about governance in the regression analysis without running into problems of multicollinearity, which occur when including the individual indicators together.
} 
institutional effectiveness. Institutional distance between traders is expected to adversely affect the intensity of trade, because traders incur adjustment costs that result from unfamiliarity and lack of skill to operate effectively in each other's institutional settings (De Groot et al. 2004). We express institutional distance as the Kogut-Singh index of distance (cf. Kogut and Singh 1988):

$$
\text { InstDist }_{i j}=\frac{1}{6} \sum_{k=1}^{6}\left(I_{k i}-I_{k j}\right)^{2} / V_{k}
$$

where $I_{k i}$ indicates the score of country $i$ on indicator $k$, and $V_{k}$ stands for the variance of indicator scores across all countries in the sample.

For data on bilateral trade and the other regressors in the gravity equation, we have used various sources. The data on trade have been taken from the United Nation's COMTRADE database, accessed through the Worldbank WITS integrated database system. For data on GDP and GDP per capita, the Worldbank World Development Indicators (WDI) was used; bilateral gravity variables were constructed using various online data sources. We refer to the Appendix at the end of the paper for more information on the data sources and for a more comprehensive discussion of the variables used in the gravity model. We have collected bilateral trade data at the macroeconomic level, as well as disaggregated by product type. Table 1 reports the trade levels and shares of total bilateral exports in the sample, for each of the product groups distinguished by Rauch (1999). ${ }^{4}$

The classification in product categories is available at Jon Haveman's data resources webpage (see the Appendix for a more detailed discussion). 
Table 1. An overview of trade per product group

\begin{tabular}{lcc}
\hline Product Group & Trade (bln. US\$, 1998) & Trade (\% share) \\
\hline Organized exchange & 319.01 & 6.9 \\
Organized exchange (excl. Petroleum) & 196.32 & 4.3 \\
Reference priced & 607.76 & 13.2 \\
Differentiated goods & 2158.41 & 46.8 \\
$\begin{array}{l}\text { Non-classified* } \\
\begin{array}{l}\text { Bilateral exports } \\
\text { (sample total) }\end{array}\end{array}$ & 1527.22 & 33.1 \\
\hline
\end{tabular}

* Not all trade flows could be classified, because not all 2-, 3- or 4 digit codes have been included in the classification.

\section{Empirical results}

\subsection{Basic results for non-zero observations}

Gravity equation (1) was estimated separately for aggregate bilateral trade and bilateral trade according to product type. For now, we confine the estimations to the observations with positive bilateral trade flows only. The gravity equations are estimated using OLS. Table 2 presents the results. Column 1 reports the results for aggregate bilateral trade. The findings confirm the well-established result that trade positively depends on GDP and negatively on distance. Furthermore, the impact of the quality of governance on trade is positive and significant, both from the export and import side. Similar to the results reported by Anderson and Marcouiller (2002), the effect of GDP per capita is insignificant or negative once the model includes institutional variables. This reflects the tendency of expenditure shares on traded goods to fall with the level of development. The expenditure pattern shifts into nontradables, notably services (not recorded in the bilateral trade statistics). 
Table 2. Gravity equations. Dependent variable: log export (per product group)

\begin{tabular}{|c|c|c|c|c|c|}
\hline $\begin{array}{l}\text { non-zero flows only } \\
\text { (trade in ' } 000 \text { US } \$ \text { ) }\end{array}$ & $\begin{array}{r}\text { Aggregate } \\
\text { Trade }\end{array}$ & $\begin{array}{r}\text { Organized } \\
\text { exchange }\end{array}$ & $\begin{array}{l}\text { Org. exch. } \\
\text { (ex. petroleum) }\end{array}$ & $\begin{array}{r}\text { Reference } \\
\text { priced }\end{array}$ & $\begin{array}{r}\text { Differentiated } \\
\text { goods }\end{array}$ \\
\hline \multirow[t]{2}{*}{ Log GDP exporter } & 1.18 & 1.02 & 0.99 & 1.05 & 1.26 \\
\hline & 86.97 & 39.39 & 39.90 & 58.85 & 86.52 \\
\hline \multirow[t]{2}{*}{ Log GDP importer } & 0.94 & 0.95 & 0.92 & 0.90 & 0.86 \\
\hline & 69.54 & 39.25 & 39.34 & 51.83 & 59.46 \\
\hline \multirow[t]{2}{*}{ Log GDP/cap exporter } & -0.09 & 0.27 & 0.11 & 0.18 & 0.02 \\
\hline & -2.19 & 3.54 & 1.53 & 3.30 & 0.40 \\
\hline \multirow[t]{2}{*}{ Log GDP/cap importer } & -0.03 & 0.00 & 0.04 & -0.21 & -0.12 \\
\hline & -0.70 & -0.05 & 0.62 & -4.13 & -2.72 \\
\hline \multirow[t]{2}{*}{ Log Distance } & -1.11 & -0.95 & -0.89 & -1.14 & -1.27 \\
\hline & -41.78 & -21.63 & -20.86 & -34.96 & -45.49 \\
\hline \multirow[t]{2}{*}{ Border Dummy } & 0.73 & 1.16 & 1.30 & 0.97 & 0.74 \\
\hline & 5.07 & 5.63 & 6.53 & 5.88 & 4.90 \\
\hline \multirow[t]{2}{*}{ Language Dummy } & 0.40 & 0.12 & 0.02 & 0.16 & 0.47 \\
\hline & 3.95 & 0.73 & 0.14 & 1.31 & 4.47 \\
\hline \multirow[t]{2}{*}{ Trade area Dummy } & 0.73 & 1.05 & 0.97 & 1.07 & 0.64 \\
\hline & 8.56 & 8.36 & 8.05 & 10.74 & 7.17 \\
\hline \multirow[t]{2}{*}{ Religion Dummy } & 0.47 & 0.18 & 0.18 & 0.30 & 0.44 \\
\hline & 9.01 & 2.06 & 2.07 & 4.65 & 8.05 \\
\hline \multirow[t]{2}{*}{ Colonial Dummy } & 0.55 & 0.62 & 0.64 & 0.56 & 0.50 \\
\hline & 6.32 & 4.19 & 4.48 & 5.12 & 5.47 \\
\hline \multirow[t]{2}{*}{ Instit. quality exporter } & 0.49 & -0.57 & -0.14 & 0.27 & 0.73 \\
\hline & 11.03 & -7.10 & -1.76 & 4.75 & 15.27 \\
\hline \multirow[t]{2}{*}{ Instit. quality importer } & 0.31 & -0.03 & -0.13 & 0.25 & 0.46 \\
\hline & 7.10 & -0.44 & -1.74 & 4.45 & 9.77 \\
\hline \multirow[t]{2}{*}{ Institutional distance } & -0.03 & -0.04 & -0.10 & -0.11 & -0.07 \\
\hline & -3.08 & -2.53 & -5.72 & -8.62 & -7.02 \\
\hline adj. $R^{2}$ & 0.71 & 0.43 & 0.44 & 0.59 & 0.71 \\
\hline number of observations & 10026 & 6089 & 6039 & 7846 & 9414 \\
\hline F-statistic & 1858.64 & 355.07 & 367.19 & 859.3 & 1771.26 \\
\hline
\end{tabular}

Note: t-statistics are reported in the line below the parameter estimates. Constant terms have been included, but are not reported in the table.

A separate column reports the gravity estimates for bilateral trade patterns in organizedexchange products excluding petroleum from the group. This serves as a robustness check on the results for organized-exchange products. Petroleum accounts for a large share of total trade in this group, while it has often been indicated that trade flows reported for this industry are prone to suffer from false reporting and misreporting (see Rauch 1999, footnote 7). The rest of the table presents the estimates for organized-exchange products, reference-priced goods and differentiated products, respectively. We first note that the hypotheses of Rauch (1999) are mostly supported by these results. The distance effect on trade indeed is more important for differentiated goods than for homogeneous goods, and least important for 
organized-exchange products. Language and religious links, as proxy for cultural familiarity and psychic distance between countries, are least important for organized-exchange goods as well. Colonial history, however, seems to be less important for differentiated than for homogeneous goods. The relative importance of colonial history for bilateral export of homogeneous goods seems to contrast with Rauch's expectations. Homogeneous products relatively frequently classify in basic industries, such as steel or resource extraction (Feenstra et al. 2001). Countries with comparative advantages in those industries include formerly colonized developing countries. Hence, the influence of resource-rich ex-colonies may explain why colonial links are relatively important for trade in homogeneous goods. Common membership in a free trade area promotes trade most in homogeneous goods. This may reflect that trade in homogeneous goods is more sensitive to price differences than trade in heterogeneous goods.

The results support the view that insecurity of contract enforcement and property rights matters most for trade in differentiated goods. The estimated trade impact of the quality of institutions in protecting property and securing trade is highest for differentiated products. The regression parameters for institutional quality in organized-exchange commodities are negative, and some are even statistically significant. This may reflect the prominence of low governance-quality developing countries among exporters of these commodities. These results for organized-exchange products are most likely related to the positive parameter estimates for per capita income. For differentiated goods and reference-priced homogeneous commodities, the estimates for both GDP per capita and institutions are more in line with the aggregate pattern. For organized-exchange products, the underlying mechanisms reflected by GDP per capita and institutions appear to be difficult to disentangle, given that they are highly correlated. The effect of institutional distance on the intensity of bilateral trade is negative, which is likely to be due to increased transaction costs caused by widely differing institutional 
settings. However, this effect does not seem to be more important for differentiated goods; if anything, it seems slightly more important for homogeneous goods.

So far, the regression analysis considered country-pair observations with positive trade flows only. It turns out that omission of zero flows from the set of observations restricts the regression sample differently across sectors. The number of zero-entried observations is largest for trade in the organized-exchange group of products. Zero flows are observed less frequently in the reference-priced group, but they still occur more often than in differentiated products. This pattern essentially reflects the law of large numbers. When a country is small or remote, or has a comparative disadvantage, we may expect that little export takes place in individual products. When considering a group of products that accounts for only a small proportion of world trade, it becomes more likely that bilateral trade is entirely missing.

Because omitting zero flows potentially causes bias in the regression estimates, differences in the share of zero flows may affect the comparability of results across product groups. Because of the large share of zero flows, uncensored observations with low expected trade are relatively underrepresented in the non-zero sample for the group of organizedexchange products. If remoteness, a lack of cultural or historical links and ineffective institutions lead to lower trade, omitting zero flows tends to reduce the estimated effects of these transaction costs on trade (cf. Rauch 1999). Therefore, the results in Table 2 may relatively underestimate the effect of, for example, distance and institutions for homogeneous as compared to differentiated goods. In the next two subsections, we aim to correct for the problem generated by zero flows, first by constructing a balanced sample so that results can be more easily compared accross different product groups (section 4.2) and second by using more advanced estimation techniques that allow for the inclusion of zero flows (section 4.3). 


\subsection{Results for a balanced sample of non-zero observations}

As a first correction for the effect of omitting zero flows, Table 3 presents the regression results after we have constructed a balanced sample of non-zero observations across sectors. The analysis considers only those observations (5694) for which trade is non-zero in all product categories. This implies that the bias resulting from the omission of zero flows is roughly equal for each sector. Moreover, using a balanced sample allows us to draw statistical conclusions about the differences in parameter estimates between product groups.

Starting from a balanced sample, the parameter estimates on exporter GDP and GDP per capita for aggregate bilateral trade are more in line with the pattern across sectors. In particular, the parameter estimate on exporter GDP per capita turns significantly positive. A sampling effect shows up clearly with respect to the distance effect on trade. Because the number of zero flows was most restrictive for organized-exchange goods, the balanced sample more closely resembles the non-zero sample of organized-exchange goods. Due to the reduced impact of low trade values in the samples for differentiated and reference-priced goods, the estimates on the distance effect are much closer across sectors. Still, an F-test on the difference in parameter estimates across product groups shows that distance is significantly more important (at a p-value of 6\%) for trade in differentiated and referencepriced goods than for organized-exchange products (excl. petroleum). ${ }^{5}$ Surprisingly, the estimated distance effect for reference-priced products is larger than for differentiated goods. Statistically, the distance effect does not differ significantly between differentiated and reference-priced goods. However, the hypothesis of parameter equality is almost rejected

\footnotetext{
${ }^{5}$ An F-test on equality of coefficients rejects the null hypothesis of equal coefficients with a p-value of $6 \%(0.2 \%)$ for differentiated (reference-priced) goods. These results were generated in Stata, using the mvreg-procedure (multivariate regression) to estimate the gravity equations for all groups as a multiple-equation regression model. This allows us to statistically test for the equality of regression coefficients across the different equations.
} 
statistically (at 12\%). The comparison of distance effects in the balanced sample thus provides less support for the search-cost view.

Table 3. Gravity equations: balanced sample. Dependent variable: log (export $\mathrm{t}_{\mathrm{ij}}$ ) (per product group)

\begin{tabular}{lrrrrr}
\hline non-zero flows only & $\begin{array}{r}\text { Aggregate } \\
\text { (trade in '000 US \$) }\end{array}$ & $\begin{array}{r}\text { Organized } \\
\text { exchange }\end{array}$ & $\begin{array}{r}\text { Org. exch. } \\
\text { (excl.petroleum) }\end{array}$ & $\begin{array}{r}\text { Reference } \\
\text { priced }\end{array}$ & $\begin{array}{r}\text { Differentiated } \\
\text { goods }\end{array}$ \\
\hline Log GDP exporter & 0.91 & 1.04 & 1.02 & 0.98 & 1.09 \\
& 71.50 & 39.33 & 39.57 & 50.62 & 67.36 \\
Log GDP importer & 0.76 & 0.98 & 0.94 & 0.87 & 0.73 \\
& 64.02 & 39.75 & 39.32 & 47.79 & 48.18 \\
Log GDP/cap exporter & 0.08 & 0.35 & 0.14 & 0.35 & 0.13 \\
& 2.10 & 4.27 & 1.73 & 5.79 & 2.52 \\
Log GDP/cap importer & -0.02 & 0.04 & 0.11 & -0.18 & -0.01 \\
& -0.67 & 0.53 & 1.45 & -3.29 & -0.30 \\
Log Distance & -0.78 & -1.00 & -0.93 & -1.06 & -1.01 \\
& -36.44 & -22.55 & -21.43 & -32.54 & -37.08 \\
Border Dummy & 0.75 & 1.15 & 1.26 & 0.98 & 0.71 \\
& 7.59 & 5.66 & 6.38 & 6.56 & 5.72 \\
Language Dummy & 0.20 & 0.08 & -0.01 & 0.01 & 0.30 \\
& 2.42 & 0.47 & -0.04 & 0.11 & 2.85 \\
Trade area Dummy & 0.80 & 1.05 & 0.98 & 0.99 & 0.63 \\
& 13.28 & 8.46 & 8.13 & 10.82 & 8.30 \\
Religion Dummy & 0.28 & 0.15 & 0.15 & 0.32 & 0.32 \\
& 6.49 & 1.72 & 1.68 & 4.82 & 5.82 \\
Colonial Dummy & 0.48 & 0.70 & 0.66 & 0.66 & 0.47 \\
& 6.57 & 4.65 & 4.55 & 6.02 & 5.13 \\
Instit. quality exporter & 0.09 & -0.61 & -0.19 & 0.06 & 0.40 \\
& 2.13 & -7.40 & -2.35 & 0.97 & 7.90 \\
Instit. quality importer & 0.20 & -0.08 & -0.20 & 0.18 & 0.28 \\
& 5.18 & -1.05 & -2.53 & 3.06 & 5.66 \\
Institutional distance & -0.03 & -0.05 & -0.10 & -0.09 & -0.07 \\
& -3.68 & -2.89 & -5.73 & -7.17 & -6.85 \\
\hline adj. R ${ }^{2}$ & 0.71 & 0.44 & 0.44 & 0.59 & 0.68 \\
number of observations & 5694 & 5694 & 5694 & 5694 & 5694 \\
F-statistic & 1098.54 & 349.38 & 348.85 & 624.88 & 922.42 \\
\hline
\end{tabular}

Note: t-statistics are reported in the line below the parameter estimates. Constant terms have been included, but are not reported in the table.

The general conclusions, when comparing the effects of language, religious and colonial links and institutions across sectors, resemble those for the unbalanced sample (see Table 2). Sharing a common language primarily benefits trade in differentiated products. The parameter estimate for common language has further declined in size for reference-priced goods, compared to the unbalanced-sample estimate. The difference in language effect, compared to 
differentiated products, is significant at $8 \%$ for organized-exchange goods and at $2 \%$ for reference-price products. Cultural links captured by common religion show a larger tradeenhancing effect in differentiated goods than in organized-exchange goods (significant at $6 \%$ ). The difference between reference-price products and differentiated goods has disappeared, however. As in the unbalanced sample, colonial links appear to be more important for trade in homogeneous products than for differentiated products. This conclusion is supported statistically for the reference-price group (at $8 \%$ ), but not for organized-exchange goods (p-value of $22 \%$ ).

The results in Table 3 confirm our hypothesis that institutions matter most for differentiated products and least for products traded on an organized exchange. Although the effect size of institutional quality falls for both reference-price and differentiated product groups, the effect on trade remains generally significant. The difference in effect size between organized-exchange goods and both reference-priced and differentiated products is statistically significant at $1 \%$. The estimates for differentiated products differ significantly from reference-priced products as well (at 10\% for importer institutions, and 1\% for exporter institutions). Differences in the effect of institutional distance across sectors are rejected statistically (at 10\%). The test outcomes weakly suggest that institutional distance may be less important for trade in the differentiated product group than in organized-exchange products or reference-priced goods (p-value of $19 \%$ and $14 \%$, respectively).

\subsection{Results including zero flows in the sample}

In the previous section, we have argued that the occurrence of zero flows can bias the empirical results. Rauch (1999) argues that disregarding zero flows leads to an underestimation of the impact of distance and historical and cultural links on trade, '[i]f zero observations tend to occur between countries that are far apart and do not share a common 
language/colonial tie' (p. 18-19). A similar reasoning holds for the effect of institutional quality on trade patterns.

Several approaches have been applied or suggested in the literature to address the problem of zero flows (e.g., see Frankel 1997, p. 145-146; Bikker 1982, p. 371-372). The most common solution in the literature confines the sample to non-zero observations to avoid the estimation problems related to zero trade. The previous section in this paper followed this procedure. However, the omission of zero flows can give rise to biased results. The zerovalued flows contain relevant information about the pattern of trade in themselves. Moreover, zero flows reflect that bilateral trade is censored from below at zero. As is well known, censoring at zero leads to estimation bias for OLS. Alternatively, (part of the) zero values may be substituted by a small constant, so that the double-log model can be estimated without throwing these country pairs out of the sample. Substituting small values prevents omission of observations from the sample, but is essentially ad hoc. Moreover, a value close to zero, substituted into the model, can bias the estimates of the gravity equation. The inserted value is arbitrary and does not necessarily reflect the underlying expected value, because the censoring nature of the data is not taken care of. Moreover, the logarithm of a small positive number is very large in absolute terms, and OLS gives larger weight to extreme observations. This may further affect the reliability of the results. Weighted least squares regression can help to mitigate this effect, but does not address the ad hoc nature of the solution.

Both approaches are hence generally insatisfactory. Throwing away zero entries implies that one loses any information contained in these flows on why these low levels of trade are observed (Eichengreen and Irwin, 1998, p. 41). Substituting zero flows with arbitrarily low numbers is also sensitive to bias. Since for our purposes small and zero-valued trade flows are more common than at the aggregate level, it is particularly important to assess the effect of omitting zero flows. 
Eichengreen and Irwin (1995) propose a transformation of the gravity model that can be estimated as a Tobit model, to account for the censoring of zero flows. For a double-log gravity equation, zero-valued observations are problematic. A log-linear model cannot explain zero-trade flows, other than when at least one of the (multiplicative) regressors is zero as well (Bikker 1982, p. 371). This will in general not be the case. In order to account for zero flows, we follow Eichengreen and Irwin $(1995,1998)$. They transform the gravity equation by adding 1 to the dependent variable before taking logs. The model to be estimated remains loglinear, but is able to handle zero entries as well. The equation can be evaluated as if it were the familiar double-log gravity equation for large values of trade, since then $\log \left(1+T_{i j}\right) \approx \log \left(T_{i j}\right)$. For very small values of trade, the function converges to a semi-log relationship, because $\log \left(1+T_{i j}\right) \approx T_{i j}$ and $\partial \log \left(1+T_{i j}\right) / \partial T_{i j}=1$ for $T_{i j}=0$. The transformed Tobit gravity model thus looks as follows:

$$
\begin{aligned}
& \ln \left(1+T_{i j}^{*}\right)=\beta_{0}+\beta_{1} \ln \left(Y_{i}\right)+\beta_{2} \ln \left(Y_{j}\right)+\beta_{3} \ln \left(y_{i}\right)+\beta_{4} \ln \left(y_{j}\right)+\beta_{5} \ln \left(D_{i j}\right)+\beta_{6} A d j_{i j} \\
& +\beta_{7} \text { Lang }_{i j}+\beta_{8} \text { PTA }_{i j}+\beta_{9} \text { Religion }_{i j}+\beta_{10} \text { Col }_{i j}+\beta_{11} \text { Inst }_{i}+\beta_{12} \text { Inst }_{j}+\beta_{13} \text { InstDist }_{i j}+\varepsilon_{i j} \\
& \ln \left(1+T_{i j}\right)=\ln \left(1+T_{i j}^{*}\right) \quad \text { if } \ln \left(1+T_{i j}^{*}\right)>0 \\
& \ln \left(1+T_{i j}\right)=0 \quad \text { if } \ln \left(1+T_{i j}^{*}\right) \leq 0
\end{aligned}
$$

The Tobit model describes both the probability that a flow is observed as zero, given the values for the regressors, and the distribution of trade, given that it is larger than zero (Verbeek 2000, p. 199). The expected value of $\ln \left(1+T_{i j}\right)$, given that actual trade is larger than zero, can be shown to exceed

$$
\begin{aligned}
& \beta_{0}+\beta_{1} \ln \left(Y_{i}\right)+\beta_{2} \ln \left(Y_{j}\right)+\beta_{3} \ln \left(y_{i}\right)+\beta_{4} \ln \left(y_{j}\right)+\beta_{5} \ln \left(D_{i j}\right)+\beta_{6} \text { Adj }_{i j} \\
& +\beta_{7} \text { Lang }_{i j}+\beta_{8} \text { PTA }_{i j}+\beta_{9} \text { Religion }_{i j}+\beta_{10} \text { Col }_{i j}+\beta_{11} \text { Inst }_{i}+\beta_{12} \text { Inst }_{j}+\beta_{13} \text { InstDist }_{i j}
\end{aligned}
$$


because of the censoring at zero. The reason is that the expectation of the mean-zero normally distributed error term, conditional on trade being larger than zero, exceeds zero. If this is not taken into account in the regression, e.g., if we estimate equation (3) only using the subsample of positive trade flows, we will not appreciate that a disproportionate part of the observations in reality has positively-biased error terms (mostly so for values of $T^{*}$, hence also $T_{i j}$, close to zero). The regression estimates thus will tend to underestimate the true parameters. The Tobit model is usually estimated through maximum likelihood (ML), and takes into account the information contained in both zero flows and positive flows. ${ }^{6}$ The Tobit model can be used when trade flows below some value are rounded to zero, or if desired trade would be negative (censoring from below). Rounding of trade flows does not seem to be apparent in our data set. Trade flows much smaller than one unit of denomination (1000 US\$ in COMTRADE) are included in the data. However, the Tobit model is appropriate if we assume that desired trade may be negative, but reported trade flows are censored from below at zero (Verbeek 2000, p. 198-199). The regression results for model (3) are presented in Table 4.

\footnotetext{
6 Eichengreen and Irwin (1995) estimate the model using scaled OLS instead of ML. Greene (1981) shows that the slope estimates of a Tobit model can be approximated by dividing the OLS estimates by the fraction of non-limit observations in the sample (i.e., scaling the OLS estimates). This is only an approximation, which is only valid for slope parameters in the regression equation, not for the constant term or for the dummy parameters.
} 
Table 4. Gravity equations: zero flows. Dependent variable: $\log (1+$ exportij) (per product group)

\begin{tabular}{|c|c|c|c|c|c|}
\hline $\begin{array}{l}\text { Tobit estimation } \\
\text { accounting for zero flows } \\
\text { (trade in '000 US } \$ \text { ) }\end{array}$ & $\begin{array}{r}\text { Aggregate } \\
\text { Trade }\end{array}$ & $\begin{array}{r}\text { Organized } \\
\text { exchange }\end{array}$ & $\begin{array}{r}\text { Org. exch. } \\
\text { (excl.petroleum) }\end{array}$ & $\begin{array}{r}\text { Reference } \\
\text { priced }\end{array}$ & $\begin{array}{r}\text { Differentiated } \\
\text { goods }\end{array}$ \\
\hline \multirow[t]{2}{*}{ Log GDP exporter } & 1.35 & 1.88 & 1.81 & 1.48 & 1.41 \\
\hline & 92.54 & 66.95 & 67.44 & 75.96 & 97.38 \\
\hline \multirow[t]{2}{*}{ Log GDP importer } & 1.08 & 1.38 & 1.32 & 1.15 & 0.98 \\
\hline & 74.22 & 51.43 & 51.41 & 59.67 & 67.84 \\
\hline \multirow[t]{2}{*}{ Log GDP/cap exporter } & -0.04 & -0.06 & -0.16 & 0.31 & 0.08 \\
\hline & -0.99 & -0.76 & -2.11 & 5.46 & 1.92 \\
\hline \multirow[t]{2}{*}{ Log GDP/cap importer } & -0.06 & -0.09 & -0.05 & -0.25 & -0.10 \\
\hline & -1.48 & -1.10 & -0.72 & -4.54 & -2.43 \\
\hline \multirow[t]{2}{*}{ Log Distance } & -1.27 & -1.83 & -1.73 & -1.62 & -1.44 \\
\hline & -43.17 & -35.83 & -35.49 & -43.07 & -49.98 \\
\hline \multirow[t]{2}{*}{ Border Dummy } & 0.56 & 1.23 & 1.36 & 0.96 & 0.54 \\
\hline & 3.41 & 4.70 & 5.47 & 4.77 & 3.42 \\
\hline \multirow[t]{2}{*}{ Language Dummy } & 0.61 & 0.59 & 0.47 & 0.66 & 0.69 \\
\hline & 5.54 & 3.06 & 2.53 & 4.63 & 6.37 \\
\hline \multirow[t]{2}{*}{ Trade area Dummy } & 0.63 & 1.16 & 1.08 & 0.98 & 0.60 \\
\hline & 6.52 & 7.41 & 7.22 & 8.20 & 6.42 \\
\hline \multirow[t]{2}{*}{ Religion Dummy } & 0.59 & 0.59 & 0.56 & 0.61 & 0.59 \\
\hline & 10.53 & 5.92 & 5.88 & 8.33 & 10.63 \\
\hline \multirow[t]{2}{*}{ Colonial Dummy } & 0.78 & 1.13 & 1.16 & 0.86 & 0.74 \\
\hline & 8.07 & 6.72 & 7.20 & 6.96 & 7.84 \\
\hline \multirow[t]{2}{*}{ Instit. quality exporter } & 0.58 & 0.11 & 0.46 & 0.55 & 0.81 \\
\hline & 12.13 & 1.35 & 5.73 & 8.83 & 17.31 \\
\hline \multirow[t]{2}{*}{ Instit. quality importer } & 0.45 & 0.38 & 0.30 & 0.51 & 0.58 \\
\hline & 9.44 & 4.47 & 3.70 & 8.27 & 12.38 \\
\hline \multirow[t]{2}{*}{ Institutional distance } & -0.01 & -0.02 & -0.07 & -0.06 & -0.05 \\
\hline & -0.72 & -0.97 & -3.70 & -3.99 & -4.75 \\
\hline $\operatorname{adj} . \mathrm{R}^{2}$ & 0.76 & 0.63 & 0.64 & 0.72 & 0.79 \\
\hline $\begin{array}{l}\text { number of observations } \\
\text { F-statistic }\end{array}$ & 11342 & 11342 & 11342 & 11342 & 11342 \\
\hline
\end{tabular}

Note: t-statistics are reported in the line below the parameter estimates. Constant terms have been included, but are not reported in the table.

After including zero flows, the results do not seem to provide strong support for the network/search view anymore. The effect of distance is smaller for differentiated products than for homogeneous goods, and largest for organized-exchange goods. The importance of proximity for trade is further reflected in a higher adjacency effect in homogeneous goods trade. Rauch (1999) provides an explanation that accounts for part of the counterintuitive finding. He constructed a measure of transportability that shows that differentiated products are roughly twice as transportable as homogeneous goods, due to lower transport costs. Rauch (1999) corrects for transportability and then finds that the results support the network view. 
Since we focus on differences in the impact of institutions on trade across product groups, we have not attempted to correct for differences in transport costs across sectors.

With respect to the other variables relevant to search costs, the differences across product groups are smaller as well, once zeros have been taken into account. Language links remain more important for differentiated products. The effect of religious similarity does not differentiate between product types. Colonial links remain strikingly more important for organized-exchange commodities, perhaps for reasons explained in section 4.1 (where we did not allow for the inclusion of zero flows).

The parameters on GDP per capita for organized-exchange products are all negative, as for aggregate bilateral trade. ${ }^{7}$ The statistically significant negative parameter estimate for exporter GDP per capita for organized-exchange products other than oil provides some support for the view that comparative advantages in these commodities are mostly located in low-income countries. Only in reference-priced and in differentiated products, the impact of exporter GDP per capita is positive, suggesting that comparative advantages are mostly in high-income countries.

The impact of governance quality remains strongest in differentiated goods, although the pattern for reference-priced products is somewhat more similar than before, especially in the impact of importer governance. In general, the estimated effect sizes on governance have increased after including zero flows in the model. For organized-exchange goods, the impact of governance quality now also generally has the expected sign (although it is small for exporter governance when petroleum products are included). This suggests that insecurity

\footnotetext{
7 The transformed gravity model in this paper produces quite large estimates on GDP. Theoretically, these parameters should be close to 1 (see Anderson and Van Wincoop 2003). Possibly, the high parameter estimates are related to the larger sample of countries in this paper, including many developing countries. Fontagné et al. (2002) argue that this may cause problems of non-linearities in the underlying model, particularly if there are many very small trade flows in the sample (which is the case here due to the inclusion of zero flows). Generally, the high parameter values on GDP are not unusual when correcting for zero flows (compare to Bikker and De Vos 1992).
} 
costs as a result of bad governance help explain low trade values, in particular observed zero flows. The impact of institutional distance (reflecting adjustment costs and trust in exchange) generally remains negative after correcting for zero flows, although it is smaller in size. This is not necessarily surprising, since many zero flows occur between less developed countries, which share similar, poor institutions.

\section{Summary and conclusions}

Unobserved barriers to trade appear to be important for the explanation of international trade patterns. Recent research has suggested that networks and search costs are important for explaining the size of trade and the differences in trade patterns between homogeneous and differentiated goods. Other studies emphasize the difficulties of protecting property rights and securing contract enforceability, given the prominence of incomplete contracts, in transactions that extend across national jurisdictions. This paper argues that both explanations can be combined, since the existence of poor contract enforcement aggravates the selectiveness of trade relations that are subject to high search and other transaction costs. We estimate a gravity model for trade in organized-exchange products, reference-priced and differentiated products that confirms the hypothesis. Institutions matter most for trade in differentiated products. If good governance is most important for exporting and importing differentiated goods, this may provide new insight in specialization patterns, economic development and intra-industry trade.

The large number of zero-entried trade flows, especially in the organized-exchange group, may cause bias in the regression results. If zero-flow observations tend to occur between distant countries that do not exhibit cultural or historical links, the omission of these observations tends to reduce the effects related to search and other transaction costs. A 
transformed Tobit gravity model has been estimated for each product group. The results again confirm that institutional quality affects trade in differentiated products most.

\section{References}

Anderson, J.E. (1999): Why Do Nations Trade (So Little)?, Boston College Working Papers in Economics, 428.

Anderson, J.E. and E. Van Wincoop (2003): 'Gravity with Gravitas: A Solution to the Border Puzzle', American Economic Review, 93, pp. 170-192.

Anderson, J.E. and E. Van Wincoop (2004): 'Trade Costs', Journal of Economic Literature, 42, pp. 691-751.

Anderson, J.E. and D. Marcouiller (2002): 'Insecurity and the Pattern of Trade: An Empirical Investigation', Review of Economics and Statistics, 84, pp. 342-352.

Bikker, J.A. (1982): 'Vraag-aanbodmodellen voor stelsels van geografisch gespreide markten, toegepast op de internationale handel en op ziekenhuisopnamen in Noord-Nederland', Vrije Universiteit Amsterdam, Dissertation.

Bikker, J.A. and A.F. de Vos (1992): 'An International Trade Flow Model with Zero Observations: an Extension of the Tobit Model', Cahiers Economiques de Bruxelles, 135, pp. 379-404.

Caballero, R.J. and M.L. Hammour (1996): 'Transactional Microstructure and Macroeconomic Performance: The "Fundamental Transformation” in Macroeconomics', American Economic Review, AEA Papers and Proceedings, 86, pp. 181-186.

Coleman, J.S. (1988): 'Social Capital in the Creation of Human Capital', American Journal of Sociology, 94, pp. 95-120.

Cronbach, L.J. (1951): 'Coefficient Alpha and the Internal Structure of Tests', Psychometrika, 16, pp. 297-333.

Deardorff, A.V. (1998): 'Determinants of Bilateral Trade: Does Gravity Work in a Neoclassical World?', in: J.A. Frankel (ed.), The Regionalization of the World Economy, pp. 7-22, Chicago and London: The University of Chicago Press.

Deardorff, A.V. (2004): Local Comparative Advantage: Trade Costs and the Pattern of Trade, University of Michigan Research Seminar in International Economics Working Paper, 500. 
Dixit, A.K. (2004): Lawlessness and Economics, The Gorman Lectures in Economics, Princeton and Oxford: Princeton University Press.

Eichengreen, B. and D.A. Irwin (1995): 'Trade Blocs, Currency Blocs and the Reorientation of World Trade in the 1930s', Journal of International Economics, 38, pp. 1-24.

Eichengreen, B. and D.A. Irwin (1998): 'The Role of History in Bilateral Trade Flows', in: J.A. Frankel (ed.), The Regionalization of the World Economy, pp. 33-57, Chicago and London: The University of Chicago Press.

Evenett, S.J. and W. Keller (2002): 'On Theories Explaining the Success of the Gravity Equation', Journal of Political Economy, 110, pp. 281-316.

Feenstra, R.C., J.R. Markusen and A.K. Rose (2001): 'Using the Gravity Equation to Differentiate among Alternative Theories of Trade', Canadian Journal of Economics, 34, pp. $430-447$.

Fontagné, L., M. Pajot and J.M. Pasteels (2002): 'Potentiels de commerce entre économies hétérogènes: un petit mode d'emploi des modèles de gravité', Economie et Prévision, pp. 115-139.

Frankel, J.A. (1997): Regional Trading Blocs in the World Economic System, Washington D.C.: Institute for International Economics.

Granovetter, M. (1985): 'Economic Action and Social Structure: The Problem of Embeddedness', American Journal of Sociology, 91, pp. 481-510.

Greene, W.H. (1981): 'On the Asymptotic Bias of the Ordinary Least Squares Estimator of the Tobit model', Econometrica, 49, pp. 505-513.

Greif, A. (1994): 'Cultural Beliefs and the Organisation of Society: A Historical and Theoretical Reflection on Collectivist and Individualist Societies', Journal of Political Economy, 102, pp. 912-950.

Groot, H.L.F. de, G.M. Linders, P. Rietveld and U. Subramanian (2004): 'The Institutional Determinants of Bilateral Trade Patterns', Kyklos, 57, pp. 103-123.

Grout, P.A. (1984): 'Investment and Wages in the Absence of Binding Contracts: A Nash Bargaining Approach', Econometrica, 52, pp. 449-460.

Helpman, E. and P. Krugman (1985): Market Structure and Foreign Trade, Cambridge, MA: MIT Press.

Kaufmann, D., A. Kraay and M. Mastruzzi (2003): 'Governance Matters III: Governance Indicators for 1996-2002', World Bank Policy Research Department Working Paper, Washington. 
Kogut, B. and H. Singh (1988): 'The Effect of National Culture on the Choice of Entry Mode', Journal of International Business Studies, 19, pp. 411-432

McCallum, J. (1995): 'National Borders Matter: Canada-U.S. Regional Trade Patterns', American Economic Review, 85, pp. 615-623.

North, D.C. (1990): Institutions, Institutional Change and Economic Performance, Cambridge: Cambridge University Press.

Obstfeld, M. and K. Rogoff (2001): 'The Six Major Puzzles in International Macroeconomics: Is There a Common Cause?', in: NBER Macroeconomics Annual 2000.

Olson, M. (1996): 'Big Bills Left on the Sidewalk: Why Some Nations are Rich, and Others Poor', Journal of Economic Perspectives, 10 (2), pp. 3-24.

Rauch, J.E. (1999): 'Networks versus Markets in International Trade', Journal of International Economics, 48, pp. 7-35.

Rauch, J.E. (2001): 'Business and Social Networks in International Trade', Journal of Economic Literature, 39, pp. 1177-1203.

Rauch, J.E. and V. Trindade (2002): 'Ethnic Chinese Networks in International Trade', Review of Economics and Statistics, 84, pp. 116-130.

Rodrik, D. (2000): 'How Far Will International Integration Go?', Journal of Economic Perspectives, 14 (1), pp. 177-186.

Rose, A.K. (2003): 'Which International Institutions Promote International Trade?', CEPR Discussion Paper, 3764, London.

Trefler, D. (1995): 'The Case of Missing Trade and Other Mysteries', American Economic Review, 85, pp. 1029-1046.

Van der Ploeg, F. (1987): 'Trade Unions, Investment and Unemployment', European Economic Review, 31, pp. 1465-1492.

Verbeek, M. (2000): A Guide to Modern Econometrics, Chichester: Wiley.

Wei, S.J. (2000): 'Natural Openness and Good Government', NBER Working Paper, 7765, Cambridge, MA. 


\section{Appendix. Description of data}

In the empirical analysis, we make use of both country-specific and bilateral data from various sources. Gross domestic product for exporting and importing countries are examples of country-specific variables. Geographical distance, adjacency, main language and religion, amongst others, are examples of other characteristics that we take into account for each pair of countries. We will now describe the data in more detail.

- We use bilateral exports as dependent variable, such that each country pair yields two observations, with either country as exporter or importer. We have used the UN COMTRADE database for bilateral trade flows in 1998, for a set of 114 countries. The figures focus on merchandise trade only. Reported imports were used instead of reported exports, because import data provide a better coverage. We have used mirror import flows that correspond to the export flow for each pair of exporting and importing countries. Although mirror import data have fewer missing trade observations than export data, some trade flow observations are reported missing in mirror imports whereas corresponding exports are non-zero. We have confronted missing observations in reported mirror imports with corresponding flows in reported exports; when corresponding reported exports were non-zero, these values have been substituted in reported mirror imports. Thus, only trade flows that are missing in both reported mirror imports and reported exports have been treated as zero-entried trade values (or nonavailables, in regressions that omit zero flows).

- The product-type classification developed by Rauch (1999) categorizes 5-digit SITC sectors according to product-type. The results have been aggregated into a classification at 2-, 3- and 4-digit SITC levels, which can more easily be confronted with bilateral trade data. These aggregated classifications have been taken from Jon Haveman's data resources website. ${ }^{8}$ Rauch (1999) distinguishes two classification schedules, which differ somewhat in aggregating process: a 'conservative' classification and a 'liberal' classification. The difference arises because the original product-type classification holds at the 5-digit SITC level. An aggregation to the 4-digit level introduces some ambiguity when several 5-digit items within a 4-digit sub-group have been classified as different product-types. We have used the conservative classification of products. This classification is reluctant to classify 2, 3 and 4-digit SITC sectors as homogeneous. The liberal classification more easily classifies 4-digit SITC products as homogeneous.

- Trade values per product group were constructed from COMTRADE data using the World Bank WITS interface. Product groups were defined following the classification according to Rauch at the 3- and 4 digit level of SITC Rev.2. To construct each product group, constituent 3-digit groups and 4-digit sub-groups were selected. When both 3-digit and 4-digit classification-scores were listed and information at both levels contradicted, we have only used the 3-digit classification to extract trade flows, for as far as they were not further classified at the 4-digit level. All 4-digit information available in the classification was explicitly used to classify and extract trade values per product group.

- For information on the level of GDP and GDP per capita, data from the World Development Indicators (World Bank 2000, on CD Rom) were used for 1998.

- For institutional quality, we have used the most recent and comprehensive data-set on the quality of governance available. This database was constructed for the World Bank by Kaufmann et al. (2003). Indicators from 17 different sources, constructed by 15 organisations have been combined. The data-set consists of six indicators of perceived

\footnotetext{
8 http://www.macalester.edu/research/economics/PAGE/HAVEMAN/Trade.Resources/ TradeData.html\#Rauch
} 
institutional quality. Each indicator captures some related aspects of the quality of governance. They either reflect the political process, the quality of the state apparatus and its policies, or the success of governance. We discuss these indicators in turn:

○ 'Voice and Accountability' reflects the extent to which citizens can participate in selecting government and hold her accountable for the actions taken. This score includes various characteristics of the political process as well as assessments of the independence of the media. It reflects whether citizens and business can prevent arbitrariness in the behaviour of government and enforce good governance when needed.

o 'Political Stability' refers to the perceived likelihood of the government being destabilised or overthrown by unconstitutional interference or excesses of violence against persons and possessions. These factors are highly detrimental for the continuity of policy and the stability of the economic environment.

- 'Government Effectiveness' is a measure for the quality of government inputs. It represents, amongst others, the perceived quality and independence of the bureaucracy. This indicates the ability of government to formulate and implement good policies.

○ 'Regulatory Quality' is directly focused on the quality of implemented policies. It includes the perceived incidence of policies that inhibit the market mechanism, and excessive regulation of foreign trade and business development and as such closely reflects the transaction costs that result from policy intrusion by the state in private trade.

- 'Rule of Law' indicates the quality of the legal system. It indicates society's perceived success in upholding fair and predictable rules for social and economic interaction. Essentially, it focuses on the quality of the legal system and the enforceability of contracts.

- 'Control of Corruption' represents the use of public power for private gain. It complements regulatory quality and rule of law indicators, as corruption is a direct reflection of poor governance in economic interaction. Corruption, like regulatory intrusion, affects transaction costs by adding a 'third-party' involvement to private transactions. An added component of corruption to trading costs is its arbitrary, uncertain nature.

- The data on geographical distance, common border, common primary language, common trade agreement, common dominant religion and common colonial history have been collected from diverse sources, which have been kindly made available by several researchers and research institutes on the internet. We have used the data-set from Sala-iMartin (1997) ${ }^{9}$ for religions and colonial backgrounds, Jon Haveman's International Trade Data ${ }^{10}$ for distance and contiguity, and CEPIIs gravity database ${ }^{11}$ for language. This part of our database is available upon request from the corresponding author. Some remarks on these variables are in place:

- Many costs of trade are related to geographical distance, from physical transport costs of goods and persons to the costs of cultural unfamiliarity. As conventional in the literature, geographical distance has been measured as the distance from home to foreign 'as the bird flies', using the principal city of each country as its centre of gravity. This implies that the distance between the two centres of gravity of neighbouring countries is likely to overestimate the average distance of trade between

9 http://www.columbia.edu/ xs23/data.htm.

10 http://www.macalester.edu/research/economics/PAGE/HAVEMAN/Trade.Resources/

TradeData.html\#Gravity.

11 http://www.cepii.fr/anglaisgraph/bdd/distances.htm 
them. The argument that the distance measure used leads to an overestimate of the distance of trade holds true for all pairs of countries. However, its relative impact is much larger in neighbouring countries than in countries that are far away from each other. Not all countries in our dataset were represented in the database for bilateral distances. For these countries, proxies were constructed using distances from neighbouring countries that were included in the database. For more discussion of the use and usefulness of other, more sophisticated measures of geographical distance, see Frankel (1997, chapter 4). In general, more sophisticated measures do not change the estimation results much, and cannot eliminate the measurement error for contiguous countries either.

- The common land border dummy indicates whether two countries are adjacent. Measurement error in the distance variable, as well as the effect of historical relations between adjacent countries are captured by this dummy-variable. For countries in our data set that had no adjacency data available from the main source, the CIA factbook (www.cia.gov/cia/publications/factbook) was used to determine whether they shared borders with any other country in the data set.

- To assess commonality in primary language, we have used a database collected by CEPII. They draw from the original data collected by Jon Haveman that distinguished fourteen languages: Arabic, Burmese, Chinese, Dutch, English, French, German, Greek, Korean, Malay, Persian, Portuguese, Spanish and Swedish. The data have been extended to cover more countries and languages. In case none of these applied or no data were available, the categories 'other language' and 'non available' were assigned. Using the CIA factbook, ${ }^{12}$ these countries have been checked. A dummy variable reflects whether or not two countries have the same primary language, an important aspect of cultural similarity.

- Whether pairs of countries take part in common trade agreements has been assessed using WTO data on major regional integration agreements. A dummy variable (common trade bloc) indicates whether a pair of countries enters into at least one common regional Preferential Trade Agreement.

- Cultural and/or historical ties between countries may also consist of a common dominant religion or a shared colonial past. Data for religion and colonial background have been taken from Sala-i-Martin (1997). Percentages of the population that adhere to one of seven major religions are presented. These religions are: Buddhism, Catholicism, Confucianism, Hinduism, Jewish religion, Islam, and Protestantism. For some countries, two religions were equally dominant over the others. These countries entered into the analysis with both religions as dominant religion. Commonality of dominant religion implies a value of 1 for the dummy variable 'common religion'.

- The dummy variable 'common colony' reflects for each pair of countries whether both of them share a similar colonial history. The data considered the British, French and Spanish empires only. We also included the colonizers themselves into the respective empires, contrary to the original source. In this way, the figures identify shared colonial relations for pairs of countries.

12 http://www.cia.gov/cia/publications/factbook/ 